\title{
The modulation of corticosteroid metabolism by hydrocortisone therapy in patients with hypopituitarism increases tissue glucocorticoid exposure
}

\author{
Mark Sherlock 1,2,", Lucy Ann Behan 2,3,*, Mark J Hannon ${ }^{3}$, Aurora Aragon Alonso', \\ Christopher J Thompson ${ }^{3}$, Robert D Murray ${ }^{4}$, Nicola Crabtree ${ }^{5}$, Beverly A Hughes ${ }^{1}$, \\ Wiebke Arlt' ${ }^{1}$, Amar Agha ${ }^{3}$, Andrew A Toogood' ${ }^{1}$ and Paul M Stewart ${ }^{6}$ \\ ${ }^{1}$ Centre for Endocrinology, Diabetes and Metabolism, University of Birmingham, Birmingham, UK, \\ ${ }^{2}$ Department of Endocrinology and Diabetes, Adelaide and Meath Hospitals, Incorporating the National Children's \\ Hospital and Trinity College, Tallaght Hospital, Dublin 24, Ireland, ${ }^{3}$ Department of Endocrinology, \\ Diabetes and Metabolism, Beaumont Hospital and RCSI Medical School, Dublin, Ireland, \\ ${ }^{4}$ Department of Endocrinology, Leeds Teaching Hospitals NHS Trust, St James's University Hospital, Leeds, UK, \\ ${ }^{5}$ Department of Nuclear Medicine, Queen Elizabeth Hospital, Birmingham, UK and ${ }^{6}$ Department of Medicine and \\ Endocrinology, University of Leeds, Leeds, UK \\ *(M Sherlock and L A Behan contributed equally to this work)
}

Correspondence should be addressed to M Sherlock

Email

sherloma@tcd.ie

\begin{abstract}
Context: Patients with hypopituitarism have increased morbidity and mortality. There is ongoing debate about the optimum glucocorticoid (GC) replacement therapy.

Objective: To assess the effect of GC replacement in hypopituitarism on corticosteroid metabolism and its impact on body composition.

Design and patients: We assessed the urinary corticosteroid metabolite profile (using gas chromatography/mass spectrometry) and body composition (clinical parameters and full body DXA) of 53 patients (19 female, median age 46 years) with hypopituitarism (33 ACTH-deficient/20 ACTH-replete) (study A). The corticosteroid metabolite profile of ten patients with ACTH deficiency was then assessed prospectively in a cross over study using three hydrocortisone $(\mathrm{HC})$ dosing regimens (20/10 mg, 10/10 mg and 10/5 mg) (study B) each for 6 weeks. 11 beta-hydroxysteroid dehydrogenase 1 (11ß-HSD1) activity was assessed by urinary THF $+5 \alpha-\mathrm{THF} / \mathrm{THE}$.

Setting: Endocrine Centres within University Teaching Hospitals in the UK and Ireland.

Main outcome measures: Urinary corticosteroid metabolite profile and body composition assessment.

Results: In study A, when patients were divided into three groups - patients not receiving $\mathrm{HC}$ and patients receiving $\mathrm{HC} \leq 20 \mathrm{mg} /$ day or $\mathrm{HC}>20 \mathrm{mg} /$ day - patients in the group receiving the highest daily dose of $\mathrm{HC}$ had significantly higher waist-to-hip ratio (WHR) than the ACTH replete group. They also had significantly elevated THF $+5 \alpha-\mathrm{THF} / \mathrm{THE}$ $(P=0.0002)$ and total cortisol metabolites $(P=0.015)$. In study $B$, patients on the highest $\mathrm{HC}$ dose had significantly elevated total cortisol metabolites and all patients on $\mathrm{HC}$ had elevated THF $+5 \alpha-\mathrm{THF} / \mathrm{THE}$ ratios when compared to controls. Conclusions: In ACTH-deficient patients daily HC doses of $>20 \mathrm{mg} /$ day have increased WHR, THF $+5 \alpha-\mathrm{THF} / \mathrm{THE}$ ratios and total cortisol metabolites. GC metabolism and induction of 11ß-HSD1 may play a pivitol role in the development of the metabolically adverse hypopituitary phenotype.
\end{abstract} Printed in Great Britain
European Journal of

Endocrinology

(2015) 173, 583-593 


\section{Introduction}

Patients with hypopituitarism have increased morbidity and mortality (1), with an all-cause standardised mortality ratio (SMR) elevated in men and women (2) and with most studies reporting increased cardiovascular (3) and cerebrovascular events $(4,5)$. The exact mechanisms underpinning this increased mortality have not been fully elucidated and a number of possible factors have been postulated, including metabolic and body composition changes in patients who have anterior pituitary dysfunction, combined with the relative impact of pharmacological therapies used to replace these deficiencies (1).

Patients on conventional replacement therapy for hypopituitarism (excluding GH replacement therapy) exhibit abnormalities of protein, fat and carbohydrate metabolism, which contributes to the reduced lean mass, increased fat mass and abnormal body composition observed. There is a propensity to central obesity and visceral fat deposition is significantly increased compared to control subjects with similar BMI $(6,7)$. In the general population, visceral adiposity is associated with the metabolic syndrome, insulin resistance/diabetes mellitus, hypercholesterolemia and hypertension $(8,9)$.

The role of adrenocorticotrophin (ACTH) deficiency and glucocorticoid (GC) replacement on morbidity and mortality in this patient group is under increasing scrutiny. Cortisol production rates in normal subjects are considerably less than those defined from isotope studies in the 1960s-1970s (10, 11). In recent years, endocrinologists have tried to decrease GC replacement doses to levels that ensure adequate replacement but do not lead to overtreatment. In a large cohort of patients with acromegaly, we have recently shown that ACTH deficiency and hydrocortisone (HC) doses of $>25 \mathrm{mg} /$ day are independently associated with increased mortality (12). Fillipson et al. (13) have described an adverse metabolic profile in a cohort of growth hormone (GH)-deficient hypopituitary patients receiving higher doses of GC replacement.

It is possible that subtle increases in GC exposure in patients on GC replacement therapy over prolonged periods might contribute to increased morbidity, as occurs in patients with Cushing's syndrome $(14,15)$.

A further confounding issue is the tissue regulation of GC action through the two isozymes of 11 beta-hydroxy-

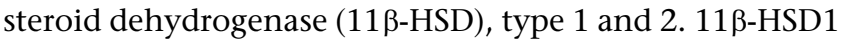
is responsible for the activation of cortisol from cortisone in key metabolic tissues including liver, adipose tissue and muscle (16). Expression and activity of 11ß-HSD1 has been implicated in many of the features of metabolic syndrome, notably hepatic glucose output, the accumulation of visceral adipose tissue and muscle insulin resistance (16). In vitro, GCs themselves positively regulate 11ß-HSD1 mRNA and activity (16).

On this background we hypothesised that corticosteroid metabolism is altered in hypopituitarism due to supraphysiological GC replacement therapy and the ensuing increase in tissue-specific cortisol metabolism contributes to the changes in body composition.

The aim of this study was to assess the effect of HC therapy on corticosteroid metabolism and $11 \beta$-HSD1 in vivo by assessing the urinary corticosteroid metabolite profile in hypopituitary patients and to analyse the potential impact on body composition.

\section{Study methods and design}

\section{Cross-sectional study patients (study A)}

Fifty-three subjects with severe GH deficiency (GHD) were recruited. GHD patients remained GH therapy naïve until the study was completed. Subjects were categorised as those with ACTH deficiency on GC replacement and those who were ACTH-replete (not requiring exogenous GCs). All subjects had pituitary disease. While taking their routine $\mathrm{HC}$ doses and other hormone replacement therapies (stable for at least 3 months), each patient provided a 24-h urine collection for assessment of corticosteroid metabolites and underwent dual energy X-ray absorptiometry (DXA) scan for body composition as well as clinical measurements of body composition.

\section{Prospective study patients (study B)}

Ten adult male hypopituitary patients with known severe ACTH deficiency on dynamic testing were included in a randomised-controlled, crossover study of three different HC replacement regimens. Patients had been diagnosed and treated for pituitary tumours between 3 and 18 years prior to inclusion in the study.

All patients were on stable appropriate pituitary hormone replacement, including $\mathrm{GH}$, without alteration in dose for at least 3 months prior to and during the study. Hormone-replacement therapy regimens were not adjusted during the study period, except for HC dose, as per study protocol.

Subjects were randomised to a crossover protocol (in random order) of three commonly prescribed doses of HC; dose A - 20 mg 0800 h, 10 mg 1600 h; dose B - 10 mg 
$0800 \mathrm{~h}, 10 \mathrm{mg} 1600 \mathrm{~h}$ and dose C - $10 \mathrm{mg} 0800 \mathrm{~h}, 5 \mathrm{mg}$ $1600 \mathrm{~h}$. At the end of each 6-week treatment schedule patients underwent a physical examination that included BMI, waist circumference (WCM), baseline pituitary blood tests, fasting glucose and insulin measurement and a 24-urine collection for measurement of urinary corticosteroid metabolites. The control participants for this study were ten healthy males, matched for age, BMI and waist circumference who underwent the same biochemical investigations and clinical examination. Data regarding quality of life and serum cortisol profiles in this patient group have previously been published (17).

\section{Pituitary hormone deficiencies: definition and diagnosis}

In study $\mathrm{A}, \mathrm{GHD}$ was defined by a stimulated peak $\mathrm{GH}$ $<3 \mathrm{ng} / \mathrm{l}$ following insulin-induced hypoglycaemia or the glucagon stimulation test. ACTH deficiency was confirmed if the +30-min cortisol response to a $250 \mu \mathrm{g}$ 'short' synacthen testing was $<550 \mathrm{nmol} / 1$ (18), or the peak cortisol $<500 \mathrm{nmol} / \mathrm{l}$ following insulin-induced hypoglycaemia during an insulin stress test. In the prospective study only subjects with severe ACTH deficiency were included as defined by a basal cortisol $<100 \mathrm{nmol} / \mathrm{l}$ and a peak-stimulated cortisol $<400 \mathrm{nmol} / \mathrm{l}$ on stimulation testing. The pituitary-thyroid axis was deficient if the free thyroxine $\left(\mathrm{fT}_{4}\right)$ concentration was below the local reference range, with an inappropriately low/normal TSH. Hypothalamic-pituitary gonadal dysfunction in males was diagnosed in the setting of a low serum testosterone and inappropriately low/normal gonadotropins. Hypothalamic-pituitary gonadal dysfunction was diagnosed in premenopausal females if the patient was amenorrheic (in the presence of normoprolactinaemia) and in postmenopausal females, if the FSH was inappropriately low.

The anterior pituitary hormone assay methodologies in use in both tertiary referral centres (Queen Elizabeth Hospital, Birmingham and Beaumont Hospital, Dublin) have changed over the last 10 years; the peak cut-off values provided above relate to the assay methodologies currently in use in each centre. However, all test results were interpreted based on the peak cut-off values for the assay in use at the time of testing.

\section{Analytical methods}

Measurement of cortisol secretion and metabolism, specifically $11 \beta$-HSD1 activity was carried out via urinary gas chromatography/mass spectrometry (GC/MS). GC/MS urinary steroid analysis was carried out for both studies at the Centre for Endocrinology, Diabetes and Metabolism (CEDAM), University of Birmingham using previously reported methodology $(19,20)$. Thirty-two steroids are targeted for selected-ion-monitoring analysis, including metabolites of androgens (and precursors), mineralocorticoids (and precursors) and GCs (and precursors).

Quantitative data on excretion of individual steroids requires accurate 24-h sampling and $1 \mathrm{ml}$ of a 24-h collection for analysis. The following isotope labelled internal standards were used; $\left(9,11,12,12-{ }^{2} \mathrm{H}\right)$ cortisol and $\left(9,12,12-{ }^{2} \mathrm{H}\right)$ cortisone. The standards were calibrated by HPLC analysis of solubilised, non-labelled standard on known weight. Free steroid was extracted using Sep-pak C18 cartridges (21). The samples were then derived using $100 \mu \mathrm{l}$ of $2 \%$ methoxyamine hydrochloride in pyridine and $50 \mu \mathrm{l}$ of trimethylsilylimidazole. Lipidex chromatography was then used to purify the steroid derivative. GC/MS was carried out using a Hewlett Packard 5970 mass spectrometer and $15 \mathrm{~m}$ fused-silica capillary column, 0.25 mmID, $0.25 \mu \mathrm{m}$ film thickness (J\&B Scientific, Folsom, CA, USA) using $2 \mu$ of sample. Steroids were quantified by comparing individual peak area to the peak area of the internal standards, for cortisol fragment $605 \mathrm{~m} / \mathrm{z}$ compared to $609 \mathrm{~m} / \mathrm{z}$ and for cortisone fragment $531 \mathrm{~m} / \mathrm{z}$ compared to $534 \mathrm{~m} / \mathrm{z}$. The relative peak area was calculated and the metabolite concentration expressed as $\mu \mathrm{g} / 24 \mathrm{~h}$. A quality control (QC) was analysed with each batch. The intra and inter-assay co-efficient of variance was $<10 \%$.

The ratio of THF $+5 \alpha$-THF/THE was used as a marker of $11 \beta$-HSD1 activity, providing the UFF/UFE ratio (reflecting $11 \beta$-HSD2 activity) was normal (16). Summation of THF + $5 \alpha$-THF + THE + cortols + cortolones + UFF + UFE was used as a surrogate marker of $24-\mathrm{h}$ total cortisol metabolites as previously validated $(22,23)$. Patients' results were compared with a control cohort ( 26 men, 62 women, age range 18-60 years) as previously reported (20).

Cortisol is subsequently reduced at the C4-5 double bond to form dihydrocortisol (DHF) or dihydrocortisone (DHE) followed by hydroxylation of the 3-oxo group to form tetrahydrocortisol (THF) and tetrahydrocortisone (THE). The reduction of the $\mathrm{C} 4-5$ double bond can be carried out by either $5 \alpha$-reductase or $5 \beta$-reductase to yield respectively, while $5 \beta$-THF (THF) or $5 \alpha$-THF (allo-THF) (16) were assessed in the urine.

\section{DXA and measurement of body composition}

Whole body dual energy X-ray absorptiometry (DXA) scanning was performed to assess body composition and 
bone mineral density using a total body scanner Hologic Discovery A Analysis version 12.4 (Hologic, Inc., Bedford, MA, USA). For total fat and lean mass measurements, coefficients of variation were $<3 \%$. Regional fat mass was defined as previously reported (23). Waist region was defined within a box area between the upper part of D12 and the iliac crest and the thigh region was defined as a box positioned so that its upper border at the level of the inferior border of the hip region. Further division of waist fat was made to characterise the 'central' or 'omental' fat region. Central fat was deemed to be the area overlying the vertebrae below D12 and either side of the vertebral column.

DXA scanning was not performed in study B in view of the short duration of therapeutic intervention, which was unlikely to alter body composition.

\section{Statistical analysis}

Statistical analysis was performed using Prism for Windows version 5.0 (GraphPad Software, Inc., San Diego, CA, USA) software. Continuous data were summarised using means and s.D.s (or S.E.M.) if parametrically distributed or medians and inter-quartile ranges if non-parametrically distributed. Parametric data was compared using a paired $t$-test and non-parametric data was analysed using a Mann-Whitney test. Multiple comparisons were assessed using one-way ANOVA, with Kruskal-Wallis for non-parametric data. Repeated measures analysis was performed using the Friedman test and Dunn's multiple comparison test. Associations between variables were analysed using Pearson correlation for parametric data and Spearman rank correlation for non-parametric data. The level for statistical significance was taken at $P<0.05$.

\section{Ethics}

The cross-sectional study (study A) was approved by the local research ethics committee and Scientific Advisory Committee of the Wellcome Trust Clinical Research Facility at the Queen Elizabeth Hospital, Birmingham at which the study was performed. Patients were recruited from the Pituitary Clinic at the Queen Elizabeth Hospital, Birmingham, and gave informed written consent. The prospective study (study B) was approved by the local Medical Ethics and Research Committee in Beaumont Hospital, Dublin at which the prospective study was performed. Patients were recruited from the Pituitary Clinic at Beaumont Hospital, Dublin, and gave informed written consent.

\section{Results}

\section{Patient characteristics}

Cross-sectional study (study A) $\bullet$ In total, 53 patients (19 female) consented for the study. Baseline characteristics are detailed in Table 1. All patients had severe GHD diagnosed on stimulation testing. Of note, 32/51 (62.8\%) had an insulin-like growth factor 1 (IGF1) in the normal age-related reference range, highlighting the poor sensitivity of IGF1 as a screening test for the diagnosis of GHD. 11/19 (52.6\%) females and 22/34 (67.6\%) males were ACTH-deficient. In the ACTH-deficient group ( $n=33), 19 / 33$ patients (eight female) received $<20 \mathrm{mg}$ HC per day and 14 patients (two female) received $>20 \mathrm{mg} /$ day. Twenty-eight patients received twice daily and five patients received thrice-daily HC therapy. In addition, 19/53 patients had TSH deficiency and were

Table 1 Patient characteristics for the cross-sectional cohort (study A). Data are expressed in median and interquartile ranges.

\begin{tabular}{l}
\hline \\
\hline Age (years) \\
SBP $(\mathrm{mmHg})$ \\
DBP $(\mathrm{mmHg})$ \\
AGHDA \\
BMI $\left(\mathrm{kg} / \mathrm{m}^{2}\right)$ \\
WHR \\
Fat $(\%)$ \\
Fat mass \\
Fat-free mass \\
Hydrocortisone daily dose (mg/day)
\end{tabular}

\begin{tabular}{c}
\hline Total group \\
\hline $46(35-58.5)$ \\
$135(118.5-148.5)$ \\
$77(71.5-86)$ \\
$11.5(6-15)$ \\
$29(25-33.9)$ \\
$0.93(0.88-0.96)$ \\
$30.7(24.2-39.8)$ \\
$26.5(18.9-37.25)$ \\
$60.8(52.0-65.5)$ \\
$20(20-27.5)$ \\
\hline
\end{tabular}

\begin{tabular}{c} 
Male \\
\hline $47.5(36.7-68.2)$ \\
$134(118-148.8)$ \\
$77.5(70-86)$ \\
$9(4-13)$ \\
$28.2(25.4-31)$ \\
$0.95(0.92-0.97)$ \\
$26.2(23.7-31.3)$ \\
$22.3(19.2-31.4)$ \\
$63.4(60-68.9)$ \\
$25(20-30)$ \\
\hline
\end{tabular}

\begin{tabular}{c}
\hline Female \\
\hline $44(23-53)$ \\
$135(116-149)$ \\
$75(72-86)$ \\
$14(6-18)$ \\
$33.8(25.4-38.2)^{\star}$ \\
$0.87(0.82-0.92)^{\dagger}$ \\
$42(33.8-47.0)^{\dagger}$ \\
$35(21.6-45.8)^{\dagger}$ \\
$47.9(44.3-53.9)$ \\
$17.5(15-20)$
\end{tabular}

SBP, systolic blood pressure; DBP, diastolic blood pressure; AGHDA, assessment of growth hormone deficiency in adults; WHR, waist-to-hip ratio. * $P<0.05$, ${ }^{\dagger} P<0.0001$, female compared to male. 
receiving $\mathrm{T}_{4}$ therapy with $\mathrm{fT}_{4}$ concentrations in the normal range, while 33/53 patients had hypogonadotropic hypogonadism and were on stable sex steroid replacement therapy.

Prospective Study (study B) • Ten patients with hypopituitarism and ten matched controls consented for the study. Patient characteristics have been described in detail elsewhere (17). The aetiology of hypopituitarism was as follows: five subjects had non-functioning pituitary adenomas, two had craniopharyngioma, two had macroprolactinoma and one had successfully treated Cushing's disease (basal cortisol $87 \mathrm{nmol} / \mathrm{l}$ and peak cortisol $113 \mathrm{nmol} / \mathrm{l}$ on dynamic testing), all had pituitary surgery and one patient had received radiotherapy. All but one subject (who had an intact hypothalamic-pituitarygonadal axis) had complete anterior hypopituitarism. Patients were on stable pituitary hormone replacement, including $\mathrm{GH}$, and were matched for age, BMI and waist circumference with control subjects (Supplementary Table 1 , see section on supplementary data given at the end of this article). There were no adrenal crises during the prospective study.

\section{Steroid metabolite excretion rates}

Study A $~-$ Metabolites of GCs were increased in patients receiving HC therapy compared to both healthy controls and patients who had hypopituitarism (and severe GHD) but who were not ACTH-deficient (Fig. 1).

To further clarify, we analysed the total cortisol (F) metabolites (Fig. 2a) ( $\mu \mathrm{g} / 24 \mathrm{~h}), \mathrm{THF}+5 \alpha$-THF/THE (a measure of global 11ß-HSD1 activity) (Fig. 2b) and urinary free cortisol (Fig. 2c) in patients with normal ACTH reserve and patients receiving $\mathrm{HC}$ doses $<20 \mathrm{mg} /$ day or $>20 \mathrm{mg} /$ day. There was an increase in total cortisol metabolites at higher doses of HC (Fig. 2a), but also a higher $\mathrm{THF}+5 \alpha-\mathrm{THF} / \mathrm{THE}$ ratio (Fig. 2b) in patients receiving both doses of $\mathrm{HC}$, but no change in urinary free cortisol levels between the groups (Fig. 2c). There was no difference in UFF/UFE ratio, a marker of $11 \beta$-HSD2 activity between the groups.

Another key component of GC metabolism is $5-\alpha$ reductase clearance. We assessed the 24-h excretion

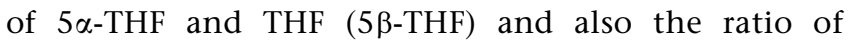
$5 \alpha$-THF/THF. Excretion rates were higher in patients who were receiving $\mathrm{HC}$ therapy than those not receiving $\mathrm{HC}$. 5 $\alpha$-THF (ACTH-deficient median 2976 (IQR 925.5-4211) $\mu \mathrm{g} / 24 \mathrm{~h}$ and ACTH replete median 1365 (IQR 444.1-2541) $\mu \mathrm{g} / 24 \mathrm{~h} P=0.06)$ and THF (ACTH-deficient median 3539
(IQR 2198-4857) $\mu \mathrm{g} / 24 \mathrm{~h}$ and ACTH replete median 1288 (IQR 1099-1998) $\mu \mathrm{g} / 24 \mathrm{~h} P=0.001$ ). However, there was no difference in the $5 \alpha$-THF/THF ratio in patients receiving HC therapy, $P=0.79$ ).

Study B $•$ Dose A (20 mg/10 mg) was associated with significantly higher total cortisol metabolites compared to the other dose regimens $(P<0.05$ vs dose $\mathrm{B}, P<0.001$ vs dose $\mathrm{C})$ and healthy controls $(P<0.01)$, while there was no difference between dose $\mathrm{B}(10 \mathrm{mg} / 10 \mathrm{mg})$, dose $\mathrm{C}$ (10 mg/5 mg) and control subjects (Fig. 3a). Although $11 \beta$-HSD1 activity was increased across all dose regimens compared to healthy controls, as demonstrated by an increased THF $+5 \alpha$-THF/THE ratio, it was highest in dose A (20 mg/10 mg) (Fig. 3b). Urinary free cortisol excretion was increased in dose A compared to dose C $(P=0.04)$ but there was no difference between the other dose regimens or compared to controls (Fig. 3c). There was no difference in UFF/UFE between controls and HC doses of 10/5 and $10 / 10$ but there was an increase in UFF/UFE ratio when comparing controls and patients receiving HC 20/10. There was no difference in UFF/UFE between the different HC doses.

We assessed the 24-h excretion of $5 \alpha$-THF and THF (5 $\beta$-THF) and also the ratio of $5 \alpha$-THF/THF in patients on different doses of HC and compared to controls. Dose A $(20 \mathrm{mg} / 10 \mathrm{mg}$ ) had higher 24 -h excretion rates of $5 \alpha$-THF $(P<0.05)$ and THF $(5 \beta-\mathrm{THF})(P<0.05)$ than healthy controls. Dose A (20 mg/10 mg) had higher 24-h excretion rates of $5 \alpha$-THF $(P<0.05)$ and THF $(5 \beta$-THF $)(P<0.01)$ than patients receiving $10 \mathrm{mg} / 5 \mathrm{mg}$ per day of $\mathrm{HC}$ but no differences were seen in patients receiving $10 \mathrm{mg} / 10 \mathrm{mg}$ HC. There was no difference in the $5 \alpha$-THF/THF ratio in controls and also in patients receiving dose A, B and C.

There was no correlation between waist circumference and any cortisol metabolite data in the prospective cohort (data not shown).

\section{Effect of HC replacement therapy and cortisol metabolism on body composition}

There was no difference in BMI or fat mass between patients who were ACTH replete and receiving $\mathrm{HC}$ replacement therapy. However, there was an increase in waist-to-hip ratio (WHR) at higher doses of HC therapy (Fig. 4). The correlation between THF + alloTHF/THE and BMI $(r=-0.43, P<0.001)$, fat mass on DXA $(r=-0.003$, $P=0.9)$, WHR $(r=+0.36, P=0.01)$ and a DXA-derived ratio of central to peripheral fat mass $(r=+0.17, P=0.41)$ was assessed in the entire group of hypopituitary patients. 

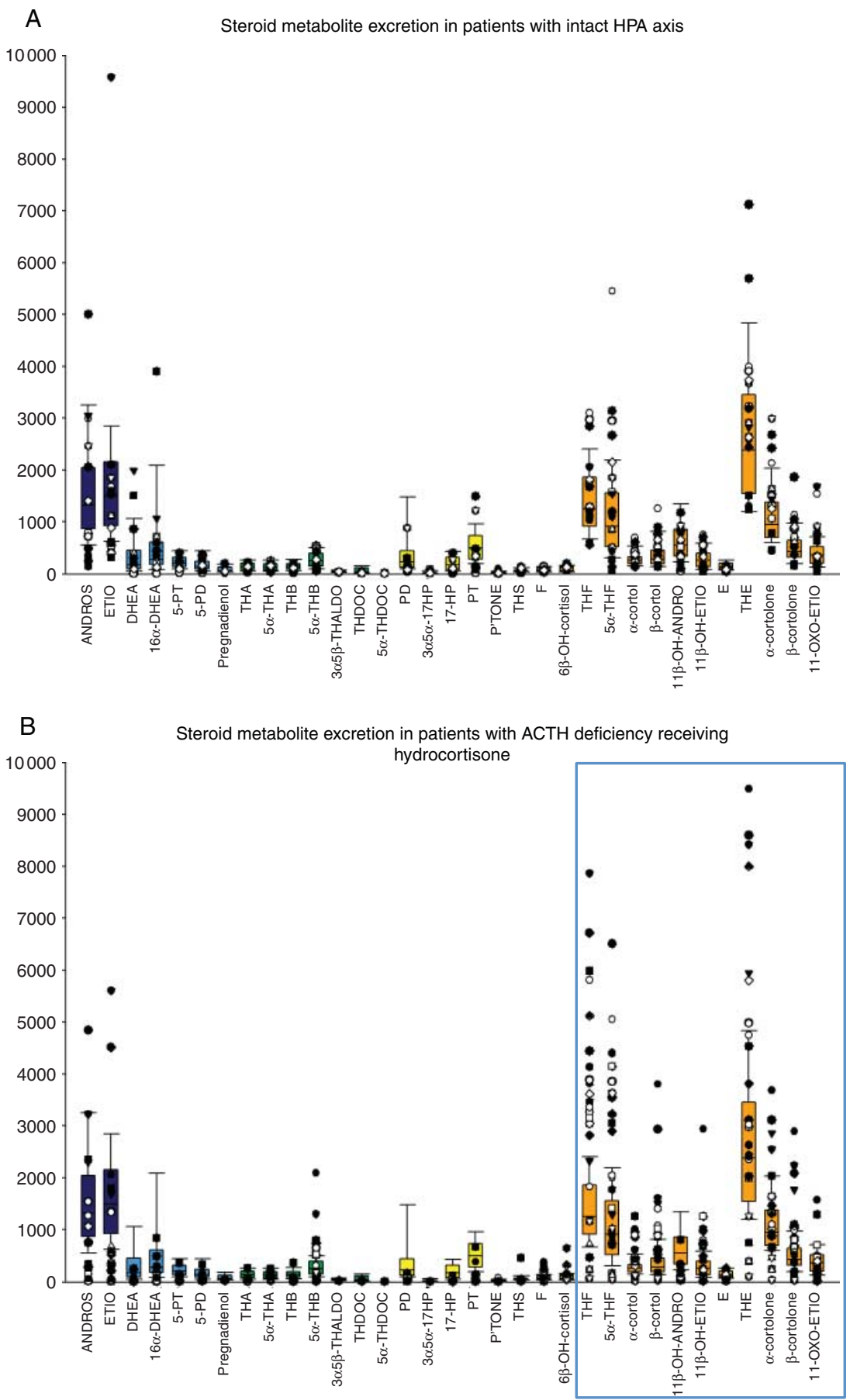

\section{Figure 1}

Representative graph of steroid metabolite excretion ( $\mu \mathrm{g} / 24 \mathrm{~h}$ ) assessed by $24-\mathrm{h}$ urinary gas chromatography/mass spectrometry in (A) patients with hypopituitarism (GHD but normal HPA axis) and (B) patients with hypopituitarism who were receiving hydrocortisone therapy for ACTH deficiency. These metabolites were divided into metabolites of androgens and precursors (blue), mineralocorticoids and precursors (green), glucocorticoid precursors (yellow) and glucocorticoids (orange). Metabolites of glucocorticoids are particularly increased in patients receiving hydrocortisone therapy ( $B$, blue box). Box and whisker plots represent mean and 5 th and 95 th percentile of healthy control group. Symbols represent individual patient results. The median hydrocortisone daily dose was $20 \mathrm{mg} /$ day and interquartile range $20-27.5 \mathrm{mg} /$ day. 
(a)

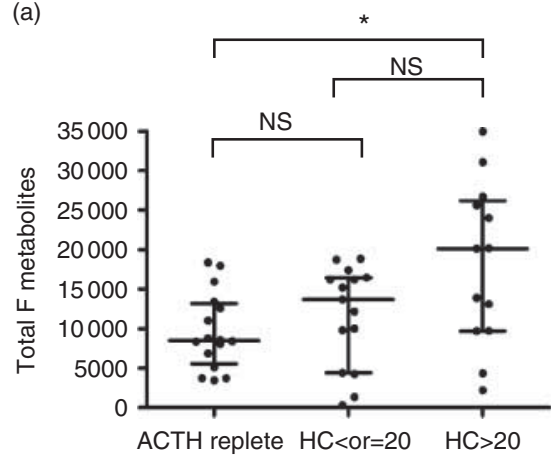

(b)

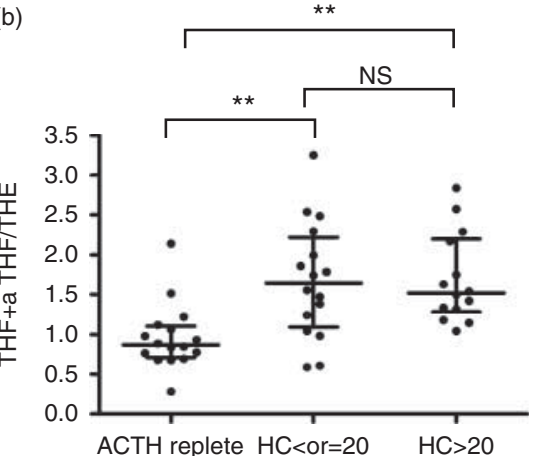

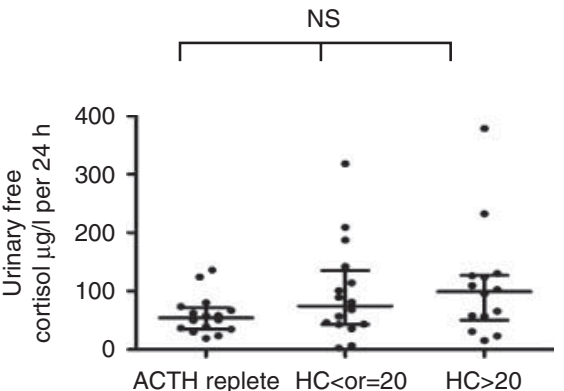

\section{Figure 2}

Differences in total cortisol (F) metabolites (a) ( $\mu \mathrm{g} / 24 \mathrm{~h}), \mathrm{THF}+$ allo-THF/THE (b) and urinary free cortisol (c) between patients with normal ACTH reserve on dynamic testing (ACTH replete) and patients receiving increasing doses of hydrocortisone $(\mathrm{HC})$ therapy (at doses less than or equal to $20 \mathrm{mg} /$ day or

There was a significant negative correlation between BMI and 11 $\beta$-HSD1 activity but no correlation for other markers of body composition.

The correlation between total cortisol metabolites and BMI $(r=-0.16, P=0.32)$, fat mass on DXA $(r=-0.17$, $P=0.3)$, WHR $(r=+0.25, P=0.1)$ and a DXA-derived ratio of central to peripheral fat mass $(r=+0.57, P<0.001)$ was assessed in the entire group of hypopituitary patients. There was a significant positive correlation between the DXA-derived ratio of central to peripheral fat mass and total cortisol metabolites but correlations for other markers of body composition were not statistically significant.
$>20 \mathrm{mg} /$ day) assessed by 24-h urinary gas chromatography/ mass spectrometry (Study A). ${ }^{*} P<0.05, * * P<0.001$, NS, not significant. Lines represent median and interquartile ranges. $\mathrm{HC}$, hydrocortisone (mg).

\section{Discussion}

These results show that patients with hypopituitarism who receive $\mathrm{HC}$ therapy have significant alterations in corticosteroid metabolism. The abnormalities reported were primarily due to an increase in total cortisol metabolites but also induction of $11 \beta$-HSD1 activity as assessed by the urinary $\mathrm{THF}+5 \alpha-\mathrm{THF} / \mathrm{THE}$ in patients receiving $\mathrm{HC}$ therapy. Importantly, there was no change in urinary free cortisol in the cross-sectional study with increasing doses of HC, suggesting that increased doses of HC were not simply excreted in the urine as the renal threshold was reached, but rather underwent intracellular metabolism.
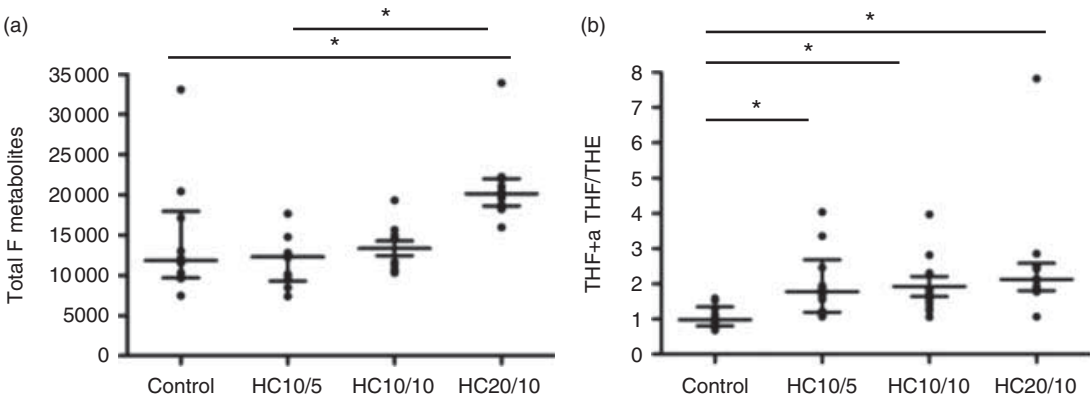

(c)

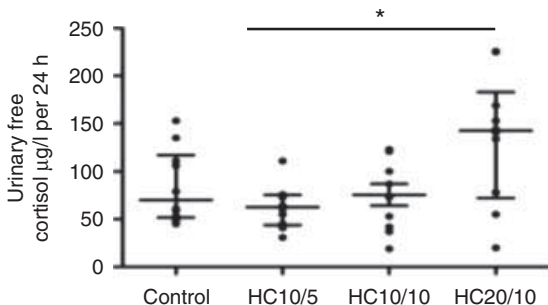

\section{Figure 3}

The effect of differing doses of hydrocortisone replacement therapy on total cortisol metabolites (a), 11 -HSD1 activity as assessed by THF + alloTHF/THE ratio (b) and urinary free cortisol (c) compared between dose groups and to healthy controls. Lines represent median and interquartile ranges. ${ }^{\star} P<0.01$. $\mathrm{HC}$, hydrocortisone in $\mathrm{mg}$. 


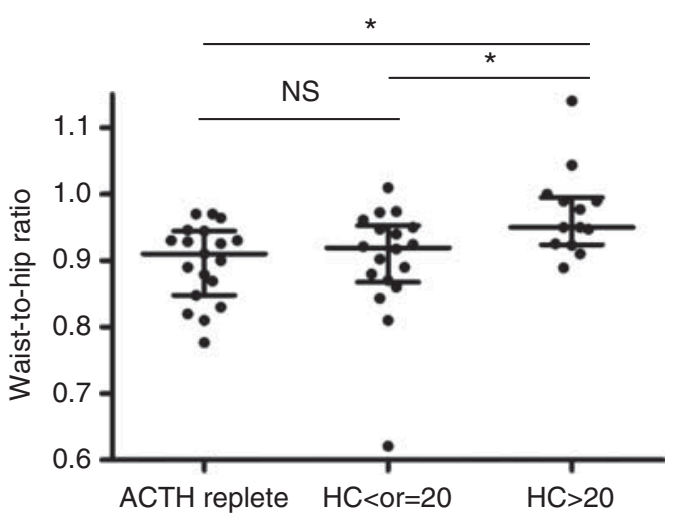

\section{Figure 4}

Differences in waist-to-hip ratio (WHR) between patients with normal ACTH reserve on dynamic testing (ACTH replete) and patients receiving increasing doses of hydrocortisone $(\mathrm{HC})$ therapy (at doses less than or equal to $20 \mathrm{mg} /$ day or $>20 \mathrm{mg} /$ day). ${ }^{*} P<0.05$, NS, not significant. Lines represent median and interquartile ranges. HC, hydrocortisone (mg).

Hypopituitarism is associated with increased morbidity and mortality (1). Recently, there has been increasing awareness that the replacement doses of HC classically used to treat patients were greater than the cortisol production rate in healthy controls $(10,11)$. Indeed, studies in patients with partial ACTH deficiency have shown similar cortisol day curves to healthy controls, suggesting that these patients are over-treated by conventional steroid replacement therapy (24). Fillipson et al. (13) described an adverse metabolic profile in a cohort of GHD (hypopituitary) patients on higher daily doses of GC replacement therapy. In patients with acromegaly, we have recently shown that ACTH deficiency is an independent predictor for mortality, with daily doses of $\mathrm{HC}$ of $>25 \mathrm{mg} /$ day associated with increased mortality, predominantly due to cardiovascular disease (12). At a molecular level there is evidence that continuous, prolonged exposure compared to intermittent short exposure to GCs may have different effects on a number of steroid-responsive enzymes (25).

In our study, patients who were on HC therapy had significant alterations in cortisol metabolism, notably an increase in total cortisol metabolites and an increased THF $+5 \alpha-$ THF/THE ratio, in keeping with induction of $11 \beta$-HSD1 activity; however, there was not a clear dose response. In study A there was an increase in total cortisol metabolites and THF + alloTHF/THE ratio in all patients receiving $\mathrm{HC}$. In study $\mathrm{B}$ there was a dose response in total cortisol metabolites and again an increase in THF + alloTHF/THE ratio in all patients receiving $\mathrm{HC}$.

These alterations in corticosteroid metabolism were associated with an increased visceral adiposity, as shown by increased WHR in patients on $>20 \mathrm{mg}$ of $\mathrm{HC}$ per day and the strong positive correlation between total cortisol metabolites and central-to-thigh fat ratio as assessed by DXA. Visceral adiposity is known in the general population to be associated with insulin resistance, diabetes mellitus, hypercholesterolaemia and hypertension $(8,9)$. Bujalska et al. (26) first proposed that excessive activity of $11 \beta$-HSD1 within visceral adipose tissue could lead to increased adipose tissue concentrations of GCs and 'Cushing's disease of the omentum'. This was endorsed in transgenic mice with over-expression of $11 \beta$-HSD1 within adipose tissue, resulting in increased tissue corticosterone concentrations and increased accumulation of central fat and adipocyte size (27).

There are a number of potential mechanisms that may link the increased central adiposity in patients with hypopituitarism receiving GC replacement therapy and alterations in 11 $\beta$-HSD1. GHD has been reported to lead to increased $11 \beta$-HSD1 activity $(28,29,30)$. In study A all patients had untreated severe GHD and in study $B$ all patients with GHD were on stable replacement doses. In study A, the greatest induction of $11 \beta$-HSD1 was seen in patients who received HC therapy, therefore it is unlikely that GHD contributes significantly - the effect is more likely secondary to exogenous GCs. Visceral adiposity and decreased lean mass are also reported in patients with GHD, and this improves following treatment with $\mathrm{GH}$ $(7,31,32,33)$. Importantly, patients in previous studies of $\mathrm{GH}$ replacement were also ACTH-deficient and on $\mathrm{HC}$ therapy. The reduction in 11 $\beta$-HSD1, following $\mathrm{GH}$ therapy (and the resultant rise in IGF1) may decrease cortisol exposure to adipose tissue and muscle, thus leading to changes in body composition $(28,29,30)$. Another putative mechanism is that GCs themselves have been reported previously to increase $11 \beta$-HSD1 activity and expression $(34,35)$, thus leading to a feed-forward regulation of $11 \beta$-HSD1 by cortisol that ultimately results in a further amplification of tissue-specific GC action.

We have shown a negative correlation between THF+ alloTHF/THE and BMI but a positive correlation between THF + alloTHF/THE and WHR. Previous data with regard to the relationship between urinary markers of $11 \beta$-HSD1 activity have been mixed, with some showing a decrease in $11 \beta$-HSD1 activity with increasing BMI $(23,36)$ while others have shown no difference $(37,38,39)$, and indeed some have shown a positive relationship $(16,40,41)$. 
This study did not use stable isotope methods for assessment of $11 \beta$-HSD in vivo. Previous studies have been performed in either healthy control subjects, obese subjects or diabetic subjects $(42,43,44,45)$. In order to accurately assess cortisol metabolism patients are infused with deuterated cortisol and metabolic products measured, which allows a more direct assessment of the relative activity of $11 \beta$-HSD1 and 2 in vivo than can be inferred by urinary metabolite assessment. These studies were not carried out in our patients but future studies using these techniques would add further information regarding the activity of $11 \beta$-HSD 1 and 2 in vivo in patients receiving $\mathrm{HC}$.

Another important pathway in GC metabolism is the 5 - $\alpha$ reductase system, which converts cortisol to its tetrahydro-metabolites.

Livingstone et al. (46) have recently published studies assessing the effects of $5 \alpha$-reductase type 1 deficiency in mice and have shown clearance of corticosterone was lower in mice with targeted disruption of $5 \alpha$-reductase type 1 compared with WT control mice. They also showed that $5 \alpha$-reductase-deficient male mice had impaired corticosterone responses to ACTH administration and stress compared with WT mice.

Tomlinson et al. (47) have also shown that GC secretion decreased, as did $5 \alpha$-reductase activity following weight loss, and this may decrease hypothalamo-pituitary-adrenal axis activation and reduce GC metabolite production. We have shown an increase in cortisol tetrahydro-metabolites in patients receiving $\mathrm{HC}$ compared with patients not receiving $\mathrm{HC}$ (study A) and also that patients receiving the highest dose of $\mathrm{HC}$ have an increase in $5 \alpha$-THF and THF. However, in all studies there was no alteration in $5 \alpha$-THF/THF ratio. Further studies are required in patients who receive $\mathrm{HC}$ therapy to assess the role of the $5 \alpha$-reductase system in more detail.

One important limitation of the cross-sectional part of this study is the heterogeneous nature of the cohort of patients with hypopituitarism (including differences in gender, body composition, rates of ACTH deficiency and HC doses), which is a common feature of many studies of patients with hypopituitarism (1). There are many other factors that may play a role in altering the set-point of cortisol-cortisone interconversion that has been reviewed in detail by Tomlinson et al. (16). A number of studies have reported an increased oxoreductase activity of $11 \beta$-HSD1 in males compared to females $(16,48)$, which will have an impact on our cross-sectional study. Instead of relying on regression analysis in an attempt to separate the effects of gender and body composition in patients receiving $\mathrm{HC}$ replacement, we performed a prospective, randomisedcontrolled study in male hypopituitary patients, with each patient receiving $\mathrm{HC}$ regimens in a crossover protocol as described above. In doing so, we were able to assess the effect of different $\mathrm{HC}$ exposure rates on cortisol metabolism within individuals and control for the confounding factors previously mentioned. Of note, we have recently shown in a rodent model that this tissue regeneration of GCs by $11 \beta$-HSD1, rather than circulating delivery, is critical to developing the phenotype of GC excess (49).

The prospective study confirmed the findings of the cross-sectional study by demonstrating significantly elevated total cortisol metabolites in higher doses of $\mathrm{HC}$ replacement, resulting in increased tissue exposure to cortisol, as evident by increased $11 \beta$-HSD1 activity across all dose regimens. These results provide further evidence that excess exogenous GC is not simply excreted by the renal system but is metabolised intracellularly, leading to significant tissue exposure and possibly contributing to the metabolic and phenotypic patterns we see in association with hypopituitarism. Given the small numbers in the prospective study, further studies are required in larger patient groups and with other measures of cortisol action and metabolism to assess the role of exogenous steroids in the development of an adverse phenotype.

In clinical practice, there are no reliable measures to ascertain if patients with adrenal insufficiency are receiving optimal GC replacement therapy. As a result, patients with adrenal insufficiency may be both over- or undertreated with GCs with resultant morbidity $(1,13)$ and mortality $(12,50)$. Steroidolomic analysis of urinary GC metabolites may offer the opportunity to optimise GC replacement therapy by aiming for metabolite concentrations and ratios in the normal range; however, further work is needed in this area.

In conclusion, this study demonstrates significant abnormalities in corticosteroid metabolism in patients with ACTH deficiency treated with conventional doses of HC therapy in keeping with increased $11 \beta$-HSD1 activity. The induction of $11 \beta$-HSD1 is associated with central adiposity. Higher doses of GC replacement therapy may directly and indirectly, via increased total corticosteroid metabolites and enhanced $11 \beta$-HSD1 activity, contribute to a deleterious metabolic phenotype. Future studies are required to assess whether urinary corticosteroid metabolites and assessment of specific urinary steroid ratios can be used as an additional surrogate biomarker of GC sufficiency in ACTH-deficient patients with hypopituitarism. 
Supplementary data

This is linked to the online version of the paper at http://dx.doi.org/10.1530/ EJE-15-0490.

\section{Declaration of interest}

The authors declare no conflict of interest related to this manuscript. M Sherlock has consulted for Viropharma.

\section{Funding}

M Sherlock was funded by the MRC as a Clinical Research Training Fellow. Study A and B were supported by unrestricted research grants from Novo Nordisk. P M Stewart is the recipient of an ERC Advanced Grant.

\section{Acknowledgements}

We would also like to thank to Liz McGregor, Jo Gray and the nurses in the Wellcome Trust Clinical Research Facility at the Queen Elizabeth Hospital, Birmingham.

\section{References}

1 Sherlock M, Ayuk J, Tomlinson JW, Toogood AA, Aragon-Alonso A, Sheppard MC, Bates AS \& Stewart PM. Mortality in patients with pituitary disease. Endocrine Reviews 201031 301-342. (doi:10.1210/er. 2009-0033)

2 Nielsen EH, Lindholm J \& Laurberg P. Excess mortality in women with pituitary disease: a meta-analysis. Clinical Endocrinology 200767 693-697. (doi:10.1111/j.1365-2265.2007.02947.x)

3 Bulow B, Hagmar L, Mikoczy Z, Nordstrom CH \& Erfurth EM. Increased cerebrovascular mortality in patients with hypopituitarism. Clinical Endocrinology 1997 46 75-81. (doi:10.1046/j.1365-2265.1997.d01-1749.x)

4 Rosen T \& Bengtsson BA. Premature mortality due to cardiovascular disease in hypopituitarism. Lancet 1990336 285-288. (doi:10.1016/ 0140-6736(90)91812-O)

5 Tomlinson JW, Holden N, Hills RK, Wheatley K, Clayton RN, Bates AS, Sheppard MC \& Stewart PM. Association between premature mortality and hypopituitarism. West Midlands Prospective Hypopituitary Study Group. Lancet 2001357 425-431. (doi:10.1016/S01406736(00)04006-X)

6 Beshyah SA, Freemantle C, Thomas E, Rutherford O, Page B, Murphy M \& Johnston DG. Abnormal body composition and reduced bone mass in growth hormone deficient hypopituitary adults. Clinical Endocrinology 199542 179-189. (doi:10.1111/j.1365-2265.1995.tb01860.x)

7 Lonn L, Kvist H, Grangard U, Bengtsson BA \& Sjostrom L. CT-determined body composition changes with recombinant human growth hormone treatment to adults with growth hormone deficiency. Basic Life Sciences $199360229-231$.

8 Haffner SM, Stern MP, Hazuda HP, Rosenthal M, Knapp JA \& Malina RM. Role of obesity and fat distribution in non-insulindependent diabetes mellitus in Mexican Americans and non-Hispanic whites. Diabetes Care 19869 153-161. (doi:10.2337/diacare.9.2.153)

9 Kissebah AH, Vydelingum N, Murray R, Evans DJ, Hartz AJ, Kalkhoff RK $\&$ Adams PW. Relation of body fat distribution to metabolic complications of obesity. Journal of Clinical Endocrinology and Metabolism 198254 254-260. (doi:10.1210/jcem-54-2-254)

10 Kerrigan JR, Veldhuis JD, Leyo SA, Iranmanesh A \& Rogol AD. Estimation of daily cortisol production and clearance rates in normal pubertal males by deconvolution analysis. Journal of Clinical Endocrinology and Metabolism 199376 1505-1510.

11 Esteban NV, Loughlin T, Yergey AL, Zawadzki JK, Booth JD, Winterer JC \& Loriaux DL. Daily cortisol production rate in man determined by stable isotope dilution/mass spectrometry. Journal of Clinical Endocrinology and Metabolism 199172 39-45. (doi:10.1210/jcem-72-1-39)

12 Sherlock M, Reulen RC, Alonso AA, Ayuk J, Clayton RN, Sheppard MC, Hawkins MM, Bates AS \& Stewart PM. ACTH deficiency, higher doses of hydrocortisone replacement, and radiotherapy are independent predictors of mortality in patients with acromegaly. Journal of Clinical Endocrinology and Metabolism 200994 4216-4223. (doi:10.1210/jc.2009-1097)

13 Filipsson H, Monson JP, Koltowska-Haggstrom M, Mattsson A \& Johannsson G. The impact of glucocorticoid replacement regimens on metabolic outcome and comorbidity in hypopituitary patients. Journal of Clinical Endocrinology and Metabolism 200691 3954-3961. (doi:10.1210/jc.2006-0524)

14 Newell-Price J, Bertagna X, Grossman AB \& Nieman LK. Cushing's syndrome. Lancet 2006367 1605-1617. (doi:10.1016/S01406736(06)68699-6)

15 Garrapa GG, Pantanetti P, Arnaldi G, Mantero F \& Faloia E. Body composition and metabolic features in women with adrenal incidentaloma or Cushing's syndrome. Journal of Clinical Endocrinology and Metabolism 200186 5301-5306.

16 Tomlinson JW, Walker EA, Bujalska IJ, Draper N, Lavery GG, Cooper MS, Hewison M \& Stewart PM. 11ß-hydroxysteroid dehydrogenase type 1: a tissue-specific regulator of glucocorticoid response. Endocrine Reviews 200425 831-866. (doi:10.1210/er.2003-0031)

17 Behan LA, Rogers B, Hannon MJ, O'Kelly P, Tormey W, Smith D, Thompson CJ \& Agha A. Optimizing glucocorticoid replacement therapy in severely adrenocorticotropin-deficient hypopituitary male patients. Clinical Endocrinology 201175 505-513. (doi:10.1111/j.13652265.2011.04074.x)

18 Clark PM, Neylon I, Raggatt PR, Sheppard MC \& Stewart PM. Defining the normal cortisol response to the short Synacthen test: implications for the investigation of hypothalamic-pituitary disorders. Clinical Endocrinology 199849 287-292. (doi:10.1046/j.1365-2265.1998.00555.x)

19 Palermo M, Shackleton CH, Mantero F \& Stewart PM. Urinary free cortisone and the assessment of 11ß-hydroxysteroid dehydrogenase activity in man. Clinical Endocrinology 199645 605-611. (doi:10.1046/j. 1365-2265.1996.00853.x)

20 Arlt W, Biehl M, Taylor AE, Hahner S, Libe R, Hughes BA, Schneider P, Smith DJ, Stiekema H, Krone $\mathrm{N}$ et al. Urine steroid metabolomics as a biomarker tool for detecting malignancy in adrenal tumors. Journal of Clinical Endocrinology and Metabolism 201196 3775-3784. (doi:10.1210/ jc.2011-1565)

21 Shackleton CH \& Whitney JO. Use of Sep-pak cartridges for urinary steroid extraction: evaluation of the method for use prior to gas chromatographic analysis. Clinica Chimica Acta 1980107 231-243. (doi:10.1016/0009-8981(80)90451-9)

22 Vassiliadi DA, Barber TM, Hughes BA, McCarthy MI, Wass JA, Franks S, Nightingale P, Tomlinson JW, Arlt W \& Stewart PM. Increased $5 \alpha$ reductase activity and adrenocortical drive in women with polycystic ovary syndrome. Journal of Clinical Endocrinology and Metabolism 2009 94 3558-3566. (doi:10.1210/jc.2009-0837)

23 Stewart PM, Boulton A, Kumar S, Clark PM \& Shackleton CH. Cortisol metabolism in human obesity: impaired cortisone $\rightarrow$ cortisol conversion in subjects with central adiposity. Journal of Clinical Endocrinology and Metabolism 199984 1022-1027.

24 Agha A, Liew A, Finucane F, Baker L, O’Kelly P, Tormey W \& Thompson CJ. Conventional glucocorticoid replacement overtreats adult hypopituitary patients with partial ACTH deficiency. Clinical Endocrinology 2004 60 688-693. (doi:10.1111/j.1365-2265.2004.02035.x)

25 Crown A \& Lightman S. Why is the management of glucocorticoid deficiency still controversial: a review of the literature. Clinical Endocrinology 200563 483-492. (doi:10.1111/j.1365-2265.2005. 02320.x) 
26 Bujalska IJ, Kumar S \& Stewart PM. Does central obesity reflect "Cushing's disease of the omentum"? Lancet 1997349 1210-1213. (doi:10.1016/S0140-6736(96)11222-8)

27 Masuzaki H, Paterson J, Shinyama H, Morton NM, Mullins JJ, Seckl JR \& Flier JS. A transgenic model of visceral obesity and the metabolic syndrome. Science 2001294 2166-2170. (doi:10.1126/science. 1066285)

28 Gelding SV, Taylor NF, Wood PJ, Noonan K, Weaver JU, Wood DF \& Monson JP. The effect of growth hormone replacement therapy on cortisol-cortisone interconversion in hypopituitary adults: evidence for growth hormone modulation of extrarenal 11ß-hydroxysteroid dehydrogenase activity. Clinical Endocrinology 199848 153-162. (doi:10.1046/j.1365-2265.1998.3641180.x)

29 Moore JS, Monson JP, Kaltsas G, Putignano P, Wood PJ, Sheppard MC, Besser GM, Taylor NF \& Stewart PM. Modulation of 11ß-hydroxysteroid dehydrogenase isozymes by growth hormone and insulin-like growth factor: in vivo and in vitro studies. Journal of Clinical Endocrinology and Metabolism 199984 4172-4177.

30 Agha A \& Monson JP. Modulation of glucocorticoid metabolism by the growth hormone - IGF-1 axis. Clinical Endocrinology 200766 459-465.

31 Abs R, Feldt-Rasmussen U, Mattsson AF, Monson JP, Bengtsson BA, Goth MI, Wilton P \& Koltowska-Haggstrom M. Determinants of cardiovascular risk in 2589 hypopituitary GH-deficient adults - a KIMS database analysis. European Journal of Endocrinology/European Federation of Endocrine Societies 2006155 79-90. (doi:10.1530/eje.1.02179)

32 Bengtsson BA, Abs R, Bennmarker H, Monson JP, Feldt-Rasmussen U, Hernberg-Stahl E, Westberg B, Wilton P \& Wuster C. The effects of treatment and the individual responsiveness to growth hormone (GH) replacement therapy in 665 GH-deficient adults. KIMS Study Group and the KIMS International Board. Journal of Clinical Endocrinology and Metabolism 199984 3929-3935. (doi:10.1210/jcem.84.11.6088)

33 Salomon F, Cuneo RC, Hesp R \& Sonksen PH. The effects of treatment with recombinant human growth hormone on body composition and metabolism in adults with growth hormone deficiency. New England Journal of Medicine 1989321 1797-1803. (doi:10.1056/ NEJM198912283212605)

34 Whorwood CB, Donovan SJ, Flanagan D, Phillips DI \& Byrne CD. Increased glucocorticoid receptor expression in human skeletal muscle cells may contribute to the pathogenesis of the metabolic syndrome. Diabetes 200251 1066-1075. (doi:10.2337/diabetes.51.4.1066)

35 Bujalska IJ, Quinkler M, Tomlinson JW, Montague CT, Smith DM \& Stewart PM. Expression profiling of 11 $\beta$-hydroxysteroid dehydrogenase type-1 and glucocorticoid-target genes in subcutaneous and omental human preadipocytes. Journal of Molecular Endocrinology 200637 327-340. (doi:10.1677/jme.1.02048)

36 Rask E, Olsson T, Soderberg S, Andrew R, Livingstone DE, Johnson O \& Walker BR. Tissue-specific dysregulation of cortisol metabolism in human obesity. Journal of Clinical Endocrinology and Metabolism 200186 1418-1421. (doi:10.1210/jcem.86.3.7453)

37 Fraser R, Ingram MC, Anderson NH, Morrison C, Davies E \& Connell JM. Cortisol effects on body mass, blood pressure, and cholesterol in the general population. Hypertension 199933 1364-1368. (doi:10.1161/01.HYP.33.6.1364)
38 Csabi GY, Juricskay S \& Molnar D. Urinary cortisol to cortisone metabolites in hypertensive obese children. Journal of Endocrinological Investigation 200023 435-439. (doi:10.1007/BF03343752)

39 Reynolds RM, Walker BR, Syddall HE, Andrew R, Wood PJ, Whorwood CB \& Phillips DI. Altered control of cortisol secretion in adult men with low birth weight and cardiovascular risk factors. Journal of Clinical Endocrinology and Metabolism 200186 245-250.

40 Rask E, Walker BR, Soderberg S, Livingstone DE, Eliasson M, Johnson O, Andrew R \& Olsson T. Tissue-specific changes in peripheral cortisol metabolism in obese women: increased adipose 11ß-hydroxysteroid dehydrogenase type 1 activity. Journal of Clinical Endocrinology and Metabolism 200287 3330-3336.

41 Andrew R, Phillips DI \& Walker BR. Obesity and gender influence cortisol secretion and metabolism in man. Journal of Clinical Endocrinology and Metabolism 199883 1806-1809. (doi:10.1210/jcem.83.5.4951)

42 Andrew R, Smith K, Jones GC \& Walker BR. Distinguishing the activities of 11ß-hydroxysteroid dehydrogenases in vivo using isotopically labeled cortisol. Journal of Clinical Endocrinology and Metabolism 2002 87 277-285.

43 Basu R, Singh RJ, Basu A, Chittilapilly EG, Johnson CM, Toffolo G, Cobelli C \& Rizza RA. Splanchnic cortisol production occurs in humans: evidence for conversion of cortisone to cortisol via the 11-beta hydroxysteroid dehydrogenase (11ß-HSD) type 1 pathway. Diabetes 200453 2051-2059. (doi:10.2337/diabetes.53.8.2051)

44 Hughes KA, Manolopoulos KN, Iqbal J, Cruden NL, Stimson RH, Reynolds RM, Newby DE, Andrew R, Karpe F \& Walker BR. Recycling between cortisol and cortisone in human splanchnic, subcutaneous adipose, and skeletal muscle tissues in vivo. Diabetes $20126 \mathbf{6 1}$ 1357-1364. (doi:10.2337/db11-1345)

45 Basu R, Singh RJ, Basu A, Chittilapilly EG, Johnson MC, Toffolo G, Cobelli C \& Rizza RA. Obesity and type 2 diabetes do not alter splanchnic cortisol production in humans. Journal of Clinical Endocrinology and Metabolism 200590 3919-3926. (doi:10.1210/ jc.2004-2390)

46 Livingstone DE, Di Rollo EM, Yang C, Codrington LE, Mathews JA Kara M, Hughes KA, Kenyon CJ, Walker BR \& Andrew R. Relative adrenal insufficiency in mice deficient in $5 \alpha$-reductase 1 . Journal of Endocrinology 2014222 257-266. (doi:10.1530/JOE-13-0563)

47 Tomlinson JW, Finney J, Hughes BA, Hughes SV \& Stewart PM. Reduced glucocorticoid production rate, decreased $5 \alpha$-reductase activity, and adipose tissue insulin sensitization after weight loss. Diabetes $2008 \mathbf{5 7}$ 1536-1543. (doi:10.2337/db08-0094)

48 Vierhapper H, Heinze G \& Nowotny P. Sex-specific difference in the interconversion of cortisol and cortisone in men and women. Obesity 200715 820-824. (doi:10.1038/oby.2007.592)

49 Morgan SA, McCabe EL, Gathercole LL, Hassan-Smith ZK, Larner DP, Bujalska IJ, Stewart PM, Tomlinson JW \& Lavery GG. 11ß-HSD1 is the major regulator of the tissue-specific effects of circulating glucocorticoid excess. PNAS 2014111 E2482-E2491. (doi:10.1073/ pnas.1323681111)

50 Bergthorsdottir R, Leonsson-Zachrisson M, Oden A \& Johannsson G. Premature mortality in patients with Addison's disease: a populationbased study. Journal of Clinical Endocrinology and Metabolism 200691 4849-4853. (doi:10.1210/jc.2006-0076)

Received 13 May 2015

Revised version received 21 July 2015

Accepted 10 August 2015 